\title{
A COMPARISON OF BRAIN THROMBOPLASTIN PREPARATIONS USED FOR TESTING PROTHROMBIN EFFICIENCY
}

\author{
BY \\ D. E. B. POWELL \\ From the Institute of Pathology, Welsh National School of Medicine, Cardiff
}

(RECEIVED FOR PUBLICATION JUNE 18, 1956)

The need for an internationally standardized preparation of thromboplastin was stressed by Barker, Best, and Wright (1948). In the absence of such a preparation, there exist many techniques for the control of anticoagulant therapy. This paper presents a comparison of two commonly used techniques, namely, those of Quick and of Toohey. The comparison shows that the methods give different results. A modification of Quick's method is described whereby the thromboplastin preparations are rendered more stable.

\section{I i Methods}

1. Quick's Method.-The method in use in this laboratory has been basically that of Quick, StanleyBrown, and Bancroft (1935), as modified later by Quick himself and others (Biggs and Macfarlane, 1949). In this method a fresh saline emulsion is prepared daily from a stock of acetone-dried human brain powder, which is kept stored in a vacuum desiccator at $4^{\circ} \mathrm{C}$.

2. Toohey's Method.-This method obviates the necessity of using dried brain extracts (Toohey, 1941, 1950; Owen and Toohey, 1941).

Fresh human brain stripped of membranes and blood vessels is simply macerated with $0.5 \% \mathrm{w} / \mathrm{v}$ phenol in $0.85 \% \mathrm{w} / \mathrm{v}$ saline. The emulsion is thoroughly shaken and kept in a tightly stoppered container at $4^{\circ} \mathrm{C}$. In a personal communication (1956) Dr. Toohey states that he no longer standardizes the preparation, but simply makes a good, thick, milky suspension which gives a normal clotting time of about $13 \mathrm{sec}$., or at the very most $14 \mathrm{sec}$.

\section{Present Investigation}

In this investigation Quick's and Toohey's methods are compared. The stability of these thromboplastin preparations is assessed and, taking the idea from Toohey's papers, dried brain extracts were emulsified with $0.5 \%(w / v)$ phenol in $0.85 \%(w / v)$ saline. The stability of these preparations is also described.

Comparison of Results Using Quick's and Toohey's Methods.-Four brain emulsions were prepared according to Toohey's directions. These gave normal clotting times of: 1, $12.5 \mathrm{sec}$., 2, $11.8 \mathrm{sec} ., 3,13.6 \mathrm{sec}$., and $\mathrm{N}$ $4,13.0$ sec. Portions of the emulsions of 1,2 , and 4 은 were taken and diluted with $0.5 \%(\mathrm{w} / \mathrm{v})$ phenol in normal saline until they gave normal clotting times of $\gg$ $14.2,13.6$, and $13.8 \mathrm{sec}$. respectively. Thus, seven brain emulsions were available for use.

Random samples of routine specimens sent to the laboratory for prothrombin estimation were taken, the $\vec{f}$ plasma separated, and the clotting time estimated both.$>$ by Quick's and Toohey's methods. All patients from whom these specimens were taken were on "dindevan " therapy. A normal control clotting time was determined for Quick's method and Toohey's method before testing any abnormal plasmas. The same normal control $\frac{\varnothing}{\varnothing}$ subject was used throughout the investigation. The $\varrho$ time given by this person corresponded closely with the $\overrightarrow{\overrightarrow{0}}$ mean clotting time of seven other normal subjects.

All estimates were done in duplicate.

The results were expressed as a simple ratio:

Prothrombin ratio (P.R.) $=\frac{\text { Patient's clotting time ( sec.) }}{\text { Normal control clotting time (sec.) }}$

TABLE I

COMPARISON OF PROTHROMBIN RATIOS BY QUICK'S COMPARISON OF PROTHROMBIN RATIOS BY QUICK'S

\begin{tabular}{|c|c|c|}
\hline $\begin{array}{c}\text { Prothrombin } \\
\text { Ratio by } \\
\text { Quick's Method }\end{array}$ & $\begin{array}{c}\text { Mean Prothrombin } \\
\text { Ratio by } \\
\text { Toohey's Method }\end{array}$ & $\begin{array}{l}\text { No. of } \\
\text { Plasmas } \\
\text { Compared }\end{array}$ \\
\hline $\begin{array}{r}1 \cdot 3 \\
1.4 \\
1 \cdot 5 \\
1.6 \\
1 \cdot 7 \\
1 \cdot 8 \\
1.9 \\
2 \cdot 0 \\
2 \cdot 1 \\
2 \cdot 2 \\
2 \cdot 3 \\
2.4 \\
2 \cdot 5 \\
2.6 \\
2.8 \\
2.9 \\
3 \cdot 0 \\
3 \cdot 1 \\
3.2 \\
3.3 \\
3.6 \\
3.9 \\
\text { c16.0 }\end{array}$ & $\begin{array}{c}1 \cdot 5 \\
2 \cdot 2 \\
2 \cdot 1 \\
1 \cdot 8 \\
2 \cdot 0 \\
2 \cdot 0 \\
2 \cdot 4 \\
2 \cdot 7 \\
3 \cdot 0 \\
2 \cdot 9 \\
4 \cdot 5 \\
3 \cdot 8 \\
3 \cdot 6 \\
4 \cdot 1 \\
5 \cdot 2 \\
5 \cdot 3 \\
4 \cdot 6 \\
4 \cdot 6 \\
6 \cdot 4 \\
5 \cdot 9 \\
4 \cdot 6 \\
8 \cdot 2 \\
\text { c32 and } \infty\end{array}$ & $\begin{array}{l}4 \\
3 \\
9 \\
2 \\
7 \\
7 \\
5 \\
3 \\
2 \\
4 \\
2 \\
2 \\
2 \\
4 \\
2 \\
2 \\
2 \\
2 \\
2 \\
1 \\
1 \\
2 \\
1\end{array}$ \\
\hline
\end{tabular}


Fresh brain emulsions for Quick's test were made up from the one sample of dried brain. This initially gave a normal control clotting time of 11 sec. but later in the investigation one of $12 \mathrm{sec}$.

\section{Comparison of Results}

Seventy-three plasmas were compared in duplicate. More plasmas were compared over the lower prothrombin ratios than over the higher, as these are the ratios used clinically. No undue variability of the results was found in either method.

It will be seen from these results (Table I) that Toohey's method gives consistently


higher ratios than Quick's

FIG. 2.-The rapid deterioration of saline emulsions of dried brain when stored at $4^{\circ} \mathrm{C}$.

method. The values from which Table I has been compiled have been analysed statistically, and the difference in the results given by the two methods is highly significant, except for the first two, that is, 1.3 and 1.4. The mean difference for all levels combined was $1.099 \pm 0.134$, where $\mathrm{t}=8.2, \mathrm{t}_{0 \cdot 0 j}=1.96$, and $\mathrm{t}_{0 \cdot 01}=2.58(\mathrm{P}<0.01)$.

The difference between the methods becomes greater as the higher ratios are compared. The correlation coefficient between the results by Quick's method and the difference between the methods is 0.71 ( 0.30 would be significant).

The ratios only are given rather than the absolute clotting times, because, in practice, the ratio guides anticoagulant therapy. The same disparity was naturally found between the clotting times, for

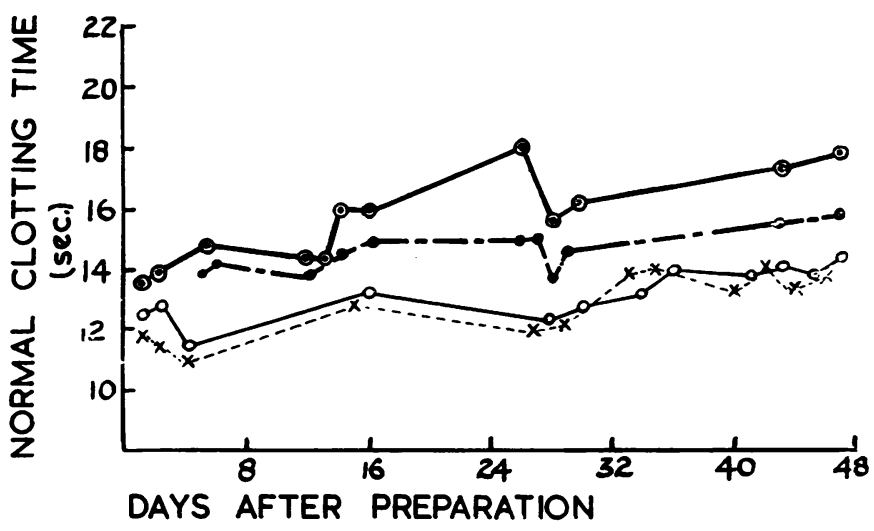

FIG. 1.-The stability of phenol-saline emulsions of wet brain preparations. example, a plasma which gave a clotting time of $15.0 \mathrm{sec}$. by Quick's method was found to give one of $26 \mathrm{sec}$. by Toohey's method. Both had the same normal control clotting time in this instance.

Stability of Fresh Phenol-saline Brain Emulsions Prepared by Toohey's Method.-These preparations showed a good degree of stability. As noted by Toohey, there may be an initial poten iiation followed by a gradual increase in the normal clotting times. The results are shown in Fig. 1. Three emulsions not charted showed similar keeping qualities.

If the maximum normal control clotting times given by these preparations is arbitrarily taken as $14 \mathrm{sec}$., as suggested by Toohey, then two emulsions which began with clotting times of $14 \mathrm{sec}$. became " unusable" within 14 days of making. The other emulsions with shorter initial clotting times remained usable for at least $\mathbf{4 0}$ days. During this period their potencies remained steady and showed little day-to-day variation.

Stability of Saline Emulsions of Acetone-dried Brain Prepared by Quick's Method.-The saline emulsions were kept at $4^{\circ} \mathrm{C}$. except when brought out for testing. The results are shown in Fig. 2.

These emulsions are obviously very unstable when kept under ordinary laboratory conditions. One exceptional specimen maintained a normal 


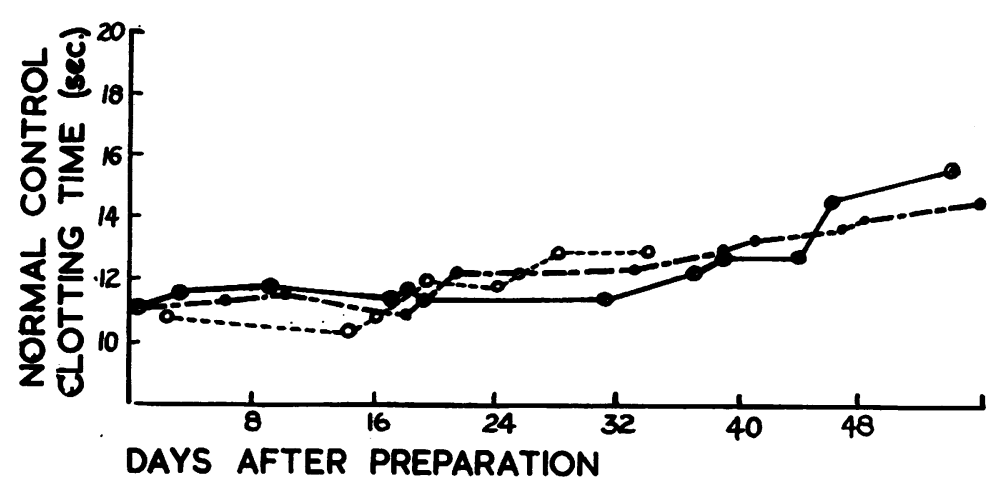

FIG. 3. The stability of saline emulsions of dried brain when $0.5 \%(w / v)$ phenol is added. emulsions, three preparations $\Rightarrow$ were made and observed? simultaneously (Fig. 5).

First Preparation.-This, a⿳亠丷厂 phenol-saline emulsion of dried $\widehat{\mathbb{D}}$ brain, was left on the bench for most of the working daye but kept in the refrigerator $\vec{\circ}$ overnight at $4^{\circ} \mathrm{C}$.

Second Preparation.-This, a saline emulsion of dried brain, was kept in the same way. $\frac{\overrightarrow{0}}{0}$

Third Preparation.-This, a phenol-saline emulsion of driedo clotting time of $12 \mathrm{sec}$. for two weeks, but thereafter it deteriorated rapidly.

The emulsions were tested on abnormal plasmas, and the prothrombin ratios compared with those obtained using freshly made emulsions. Twentyseven plasmas were compared. The results were not analysed separately according to the age of the old emulsions, but all emulsions gave equal or slightly higher prothrombin ratios than those obtained with fresh emulsions. The differences, however, were of no practical significance, and were not nearly as marked as those obtaining in the previous comparison with Toohey's method.

Stability of Phenol-saline Emulsions of Dried Brain.-These were prepared exactly as in Quick's method except that the emulsion was made up with $0.5 \%(\mathrm{w} / \mathrm{v})$ phenol in $0.85 \%(\mathrm{w} / \mathrm{v})$ saline.

The emulsions were stored at $4^{\circ} \mathrm{C}$. except when brought out for testing.

The results are shown in Fig. 3.

The emulsions showed good keeping qualities (as judged by the normal control clotting times) for at least $\mathbf{3 0}$ days. The specimen illustrated in Fig. 4 did not behave in this manner. This specimen had $0.5 \%(\mathrm{w} / \mathrm{v})$ crystalline phenol added after it had stood in the laboratory for six hours. Even so, it maintained its normal control time for 15 days.

The prothrombin ratios obtained with these emulsions were compared with those obtained using fresh dried brain emulsions. Thirty-six plasmas were compared.

These again usually give slightly higher ratios when compared with fresh extracts, but the difference was of no practical significance.

As a further check on this method of preserving the potency of dried brain brain, was kept constantly at $4^{\circ} \mathrm{C}$. except when ${ }_{0}^{N}$ brought out for testing.

Fig. 5 illustrates that Preparation 2 deteriorated $\vec{\supset}$ very rapidly. Preparations 1 and 3 remained stable Preparation 1 showed a normal clotting time of $\frac{c}{\omega}$

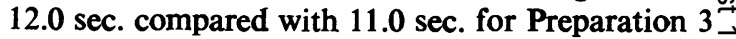
on the seventeenth day after preparation.

Finally, all the emulsions were cultured for. bacterial organisms. All the saline emulsions (all of which had deteriorated) grew coliforms profusely. All the phenol-saline emulsions yielded no growth, with one exception, namely, the emulsion illustrated by Fig. 4, which grew coliforms (and which had $\stackrel{\complement}{\mathscr{Q}}$ also deteriorated).

\section{Discussion}

While many aspects of prothrombin testing are the subject of debate, the majority of workers now용 agree that human brain is the best source of tissue $:$ thromboplastin.

Various published series which purport to demon- $\delta$ strate the value of anticoagulants in coronary

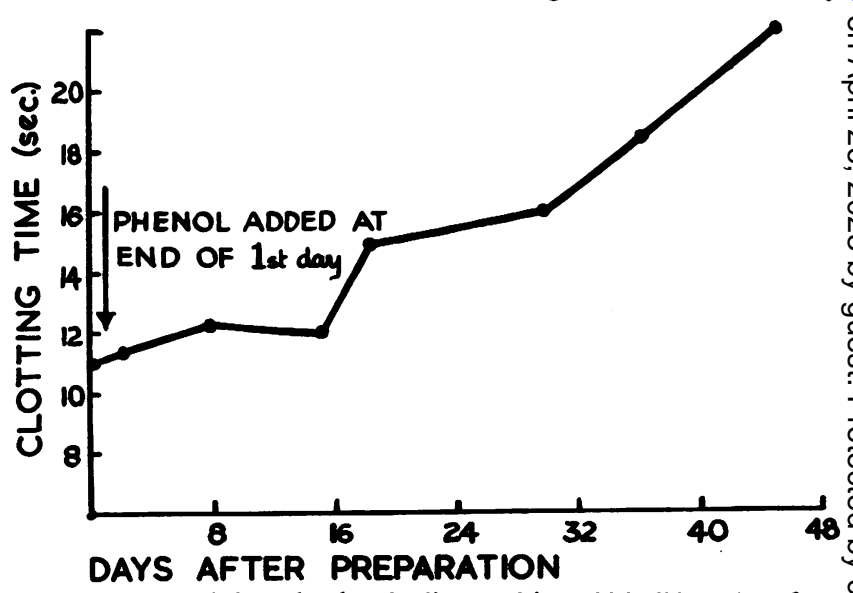

FIG. 4.-Curve of the only phenol-saline emulsion which did not keep for over two weeks. 


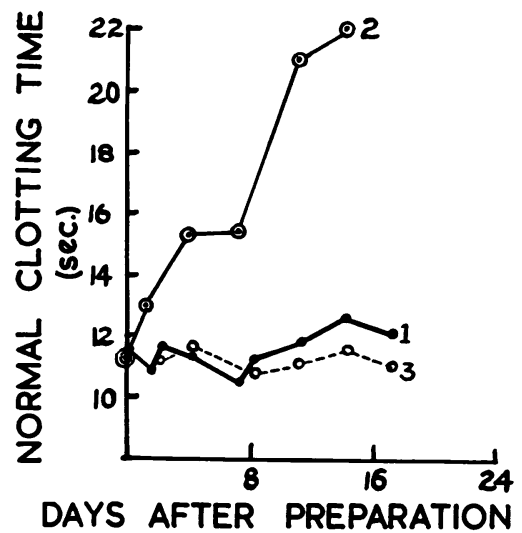

Fig. 5.-Three brain emulsions concurrently. For explanation see text.

thrombosis give a certain level of "prothrombin efficiency" as the optimum. For example, Tulloch and Gilchrist (1950) give a prothrombin ratio of 2.0 to 2.5 as the optimum. Such levels will then be the goal of other hospitals and laboratories. Biggs and Macfarlane (1953) advise $1.5-2.5$ as the best therapeutic range. If, however, the laboratory is using Toohey's method, and if the clinician keeps his patient's prothrombin ratio between 1.5 and 2.5 , then that patient is being kept at what would be a consistently and appreciably lower ratio if Quick's method were used. This, in fact, appears to have happened. Pearson (1953) published a series of 567 cases in which Toohey's method was used. The aim in the first 100 cases was a prothrombin ratio of $1.5-2.5$. Later in the series this was raised to $2.0-3.0$.

According to the above resulis the equivalent therapeutic ranges of the two methods are:

1.5-2.5 (Quick) $=2.1-3.6$ (Toohey).

2.0-3.0 ( , , ) =2.7-4.6 (,, ).

Toohey (1953) gives an absolute clotting time of 30 to $45 \mathrm{sec}$. as the optimum, or a ratio of 2.0-3.0.

All this does not mean that Quick's method is better than Toohey's, or vice versa, but, if the apparent benefit of anticoagulant therapy is related to its effect on the retarding of clotting, it follows that the method in use in reported series and in individual laboratories needs to be clearly defined. Also new methods should always be compared alongside the older, well-established methods. Some published series do not even mention the method used. Because of the larger difference over the higher levels, the haemorrhagic levels will be markedly different by the two methods.

Astrup (1948) remarked on the change in the prothrombin activity curve after brain has been dried with acetone. Thus, had a further comparison of prothrombin curves been made, it is possible that a closer correlation (or greater disparities) might have been obtained, but many workers, including Toohey (1950), believe that the absolute clotting times are of greater significance than an estimate of percentage concentration.

The differing results are also of theoretical interest. Acetone-dried brain and wet brain preparations must measure different factors or different proportions of the same factors. Quick (1942) postulated that acetone extraction removes an inhibitor substance. Brambel (1945) also noted the increased activity of acetone-dried extracts as compared with vacuum-dried extracts.

The advantages of Toohey's method are: (1) Ease of preparation; (2) there is no need to make a fresh daily emulsion; (3) a brain emulsion of known potency is immediately available for emergency testing.

From this preliminary investigation it appears that the advantages of Toohey's method can be incorporated into Quick's method, namely, by making up the emulsion of acetone-dried brain with $0.5 \%(\mathrm{w} / \mathrm{v})$ phenol in $0.85 \%(\mathrm{w} / \mathrm{v})$ saline. The emulsion should be stored at $4^{\circ} \mathrm{C}$. and only brought out for testing. A stock bottle could be kept in the refrigerator. This then should give an emulsion with a stable normal clotting time and comparable prothrombin ratio for, at the very least, two weeks. Dr. J. W. Keyser, when trying out this method, found that whereas, as is well known, deep freezing helps to preserve saline emulsions, it produces a very rapid deterioration in phenol-saline emulsions.

Quick (1942 and 1948) kept dried brain stable indefinitely in an evacuated tube or in an atmosphere of nitrogen. He kept the saline emulsion in a deep freeze for two weeks. None of these methods are practicable for routine work.

In this modification of Quick's method, a normal control should be done at least every three days.

A considerable advantage of the method is that for night or emergency prothrombin estimation it would no longer be necessary to weigh out dried brain, incubate, and suspend, a process taking about 40 minutes to perform.

It is a method which should have more extensive trial.

\section{Conclusions}

Quick's method gives shorter clotting times and lower prothrombin ratios than Toohey's method.

Dried brain when emulsified with $0.5 \%(\mathrm{w} / \mathrm{v})$ phenol in normal saline remains stable and useful for prothrombin testing for at least two weeks. 
I wish to express my gratitude to Professor J. Gough for his encouragement, and to Drs. R. M. Hardisty, J. W. Keyser, and J. L. Withey for helpful criticism. I also wish to thank Dr. E. Lewis-Faning for the statistical analysis, Dr. J. C. Griffiths for the bacteriological report, and Miss June Williams, who prepared the graphs.

\section{REFERENCES}

Astrup, T. (1948). Blood Clotting and Allied Problems: Trans. 1st Conf., p. 103. Josiah Macy, Jr. Foundation, New York.

Barker, N. W., Best, C. H., and Wright, I. S. (1948). Ibid., p. 137. Biggs, R., and Macfarlane, R. G. (1949). Journal of Clinical Pathology, 2. 33 .
Biggs, R., and Macfarlane, R. G. (1953). Human Blood Coagulation, p. 300. Blackwell, Oxford.

Brambel, C. E. (1945). Arch. Surg. (Chicago), 50, 137.

Owen, T. K., and Toohey, M. (1941). Lancet, 1, 724.

Pearson, H. E. S. (1953). Brit. med. J., $2,4$.

Quick, A. J. (1942). The Haemorrhagic Diseases, 1st ed., p. 66. Thomas, Springfield, Illinois.

(1948). Blood Clotting and Allied Problems: Trans. 1st Conf., p. 171. Josiah Macy, Jr. Foundation, New York.

Stanley-Brown, M., and Bancroft, F. W. (1935). Amer. J. med. Sci., 190, 501 .

Toohey, M. (1941). Irish J. med. Sci., 6th ser., No. 189, p. 509. (1950). Brit. med. J., 1, 518.

- (1953). Ibid., 1, 650.

Tulloch, J. A., and Gilchrist, A. R. (1950). Ibid., 2, 965. 